\title{
Thank you, Dr. Nagle
}

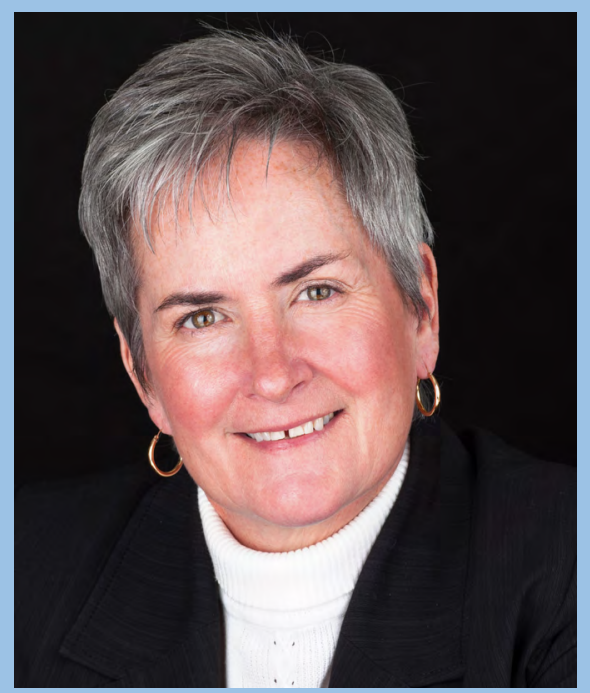

For more than 10 years, Dr. Lynn Nagle has demonstrated true nursing leadership as the editor-in-chief of this journal. Her leadership has been evident through her many, many accomplishments, some of which include establishing the Canadian Nursing Informatics Association, induction as a fellow into both the American and Canadian Academies of Nursing, being named one of the top 10 Women Leaders in Digital Health in Canada, being recognized with the CNA's Centennial Nurse Award and designation with a Distinguished Alumni award, University of Rochester - just to name a few.

In April 2010, Longwoods founder W. Anton Hart introduced Dr. Lynn Nagle as the new editor-in-chief of the Canadian Journal of Nursing Leadership (CJNL). Anton was thrilled to welcome Lynn to the team and "...to learn from her fresh perspective and keen intelligence." Lynn delivered!

This issue of CJNL will be Lynn's last issue as editor-in-chief. Longwoods, the Canadian Nurses Association, the nursing community and all of the Canadian healthcare sector have been treated to her thoughts, her opinions and her insights as she guided us through the many challenges, obstacles and triumphs that are the experiences of a nurse leader in Canada and around the world.

We have been honoured to have Lynn lead the CJNL for 48 issues and multiple special issues. We wish her all the best and look forward to any future projects and initiatives that we can work on together.

Personally, watching and learning from Lynn, when the opportunity was presented, offered tremendous value. As many have realized through their own experiences, my relationship with Lynn has helped me to grow.

Thank you, Lynn.

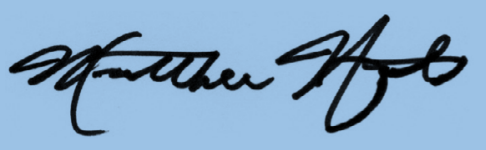

Matthew Hart 